\title{
The Genoa Method in Alcohol Dependence Treatment
}

\author{
Gianni Testino ${ }^{\mathrm{a}, \mathrm{b}}$, Alessandro Sumberaz ${ }^{\mathrm{a}}$, Paolo Borro ${ }^{\mathrm{a}}$
}

\section{To the Editor}

Alcohol consumption is a major public health problem in Europe, resulting in $3.8 \%$ of all deaths and $4.6 \%$ of years of life lost due to disability [1]. The overall cost of alcoholic disease is more than that of smoking tobacco $[1,2]$.

Currently in the European Union, only $10 \%$ of alcohol dependence $(\mathrm{AD})$ patients are treated. In the United States, this happens in $25 \%$ of cases [1]. It is evident that a new way of working is necessary.

As indicated in our previous papers $[1,3]$, the treatment of $\mathrm{AD}$ will be increasingly aimed at a truly tailored therapy that takes into account the type of AD (Cloninger or Lesch's), the type of craving (reward, relief and obsessive), the presence of other addictions, the presence of comorbidities both internistic and psychiatric, and the pharmacogenomics [4].

In literature, there is only one report about a new way of treatment in AD patients [5]. Siva [5] showed a new way of working within AD. It is to ensure rapid access to a specialist detox center (rapid access to acute alcohol detoxification referrals: RADAR).

This modified way of working has been at the San Martino Hospital in Genoa since 2005. The approach is an immediate action multidisciplinary clinic with the offer of immediate self-help groups for patients and family members. In addition, the monitoring of the activity and, therefore, the outcome has been put in relation to the period of sobriety and the onset of liver cirrhosis.

The recent retrospective evaluation (2005 - 2010) of a group of young patients under the age of 25 took over as the immediate task of receiving hospital care in combination with self-help groups to ensure the best outcome.

One hundred one young patients with a mean age of 22 years (20 - 24 years) were enrolled rapidly (within $24 \mathrm{~h}$ after acute) and put into a multidisciplinary care pathway. The team was accompanied by self-help groups. This group was

Manuscript accepted for publication February 12, 2016

${ }^{a}$ Alcohologic Regional Centre, Ligurian Region, IRCCS AOU San MartinoIST Genoa, Italy

${ }^{b}$ Corresponding Author: Gianni Testino, Alcohologic Regional Centre, Ligurian Region, IRCCS AOU San Martino-IST Genoa, Italy.

Email: gianni.testino@hsanmartino.it

doi: http://dx.doi.org/10.14740/gr700e compared with 130 younger patients with a mean age of 22 years (20 - 24 years), which for various reasons followed a traditional route.

The diagnosis of AD was carried out through the DSM-IV.

After 5 years, we evaluated some variables by univariate analysis of the period of sobriety, and the onset of cirrhosis and hepatocellular carcinoma (HCC). With multivariate analysis, the sobriety variable was linked to the onset of cirrhosis.

The diagnosis of cirrhosis was carried out through a clinical laboratory assessment and through the histological evaluation and/or the use of quantitative elastographic features. Since June 2015, the elastography assessment has been performed with Share Wave (RS80 with Prestige - Samsumg Electronics, Italy). The diagnosis of HCC with two imaging techniques is concordant (contrast enhanced ultrasound plus computed tomography and/or magnetic resonance) $[6,7]$.

Univariate and multiple logistic regression analysis was performed to identify the demographic variables and outcomes associated with self-help groups (JMP, SA, NC, USA). The covariates were significant at 0.10 in the univariate analysis and were further top evaluated for inclusion in multivariable regression models, using a stepwise algorithm. All the tests were two-tailed, and a P-value $<0.05$ was determined to represent statistical significance.

It has emerged that an early enlistment in combination with the presence of a self-help group will guarantee a period of sobriety longer in years than in a group with conventional treatment: $6(4-7)$ vs. $3(3-6)(\mathrm{P}<0.0001)$. Cases of cirrhosis (20.7\% vs. $26.15 \%)$ and HCC (9\% vs. $13 \%)$ tend to be lower.

Multivariate analysis found that sobriety reduced the risk of cirrhosis by 23 times: LR 301.06, Chi-square $(\mathrm{P}<0.0001)$, odds ratio (95\% CI): 23.5 (1.15 - 2.26) $(\mathrm{P}<0.0001)$.

In the literature, approaches of this kind are not described. They are to be proposed at the international approach RADAR and Genoa with the advice of a real involvement already in the initial stages of a self-help group (within $24 \mathrm{~h}$ ). The synergy of the rapid intervention multidisciplinary associations of selfhelp may be particularly important for maintaining abstinence over time and reducing healthcare costs.

\section{References}

1. Testino G, Leone S, Borro P. Treatment of alcohol dependence: recent progress and reduction of consumption. Minerva Med. 2014;105(6):447-466.

2. Rehm J, Zatonksi W, Taylor B, Anderson P. Epidemiology 
and alcohol policy in Europe. Addiction. 2011;106(Suppl 1):11-19.

3. Borro P, Leone S, Testino G. Liver Disease and Hepatocellular Carcinoma in Alcoholics: The Role of Anticraving Therapy. Curr Drug Targets. 2016;17(2):239-251.

4. Addolorato G, Mirijello A, Leggio L, Ferrulli A, Landolfi R. Management of alcohol dependence in patients with liver disease. CNS Drugs. 2013;27(4):287-299.

5. Siva N. Tackling the UK's alcohol problems. Lancet.
2015;386(9989):121-122.

6. Testino G, Leone S, Borro P. Alcohol and hepatocellular carcinoma: a review and a point of view. World J Gastroenterol. 2014;20(43):15943-15954.

7. Testino G, Burra P, Bonino F, Piani F, Sumberaz A, Peressutti R, Giannelli Castiglione A, et al. Acute alcoholic hepatitis, end stage alcoholic liver disease and liver transplantation: an Italian position statement. World J Gastroenterol. 2014;20(40):14642-14651. 